\title{
STUDI EKSPERIMENTAL BALOK KAYU LAMINASI DENGAN VARIASI MODULUS ELASTISITAS DAN BENTUK PENAMPANG
}

\author{
Alvianti ${ }^{\text {区 }}$, Johannes Adhijoso Tjondro ${ }^{2}$ \\ ${ }^{1}$ Mahasiswi, Program Magister Teknik Sipil, Universitas Katolik Parahyangan , Jl Ciumbuleuit 94 \\ Bandung \\ ${ }^{2}$ Dosen, Program Magister Teknik Sipil, Universitas Katolik Parahyangan , Jl Ciumbuleuit 94 Bandung \\ ${ }^{\square}$-mail : via.alvianti@gmail.com
}

\begin{abstract}
Timber glulam beam is used to get the required cross section dimension. The aims of this study is to find the optimal bending capacity of the glulam cross section from 4 boards. Another purpose is to compare the bending behavior of Albasia glulam beams and the combination of Albasia-Meranti timber material. The timber beams are arranged into solid rectangular, I, and box section using epoxy adhesives. The basis design for I and box section is the smallest shear flow at web and flange connections. Meranti timber is used as flange of I and box section at combined timber material beams. The method to test bending behaviour is third point loading. Bending capacity and ductility of full Albasia glulam beams is the highest compared to full Albasia glulam solid rectangular and box section. Meranti timber as flange of I and box section glulam beams increase the bending capacity up to $44.41 \%$ and $57.56 \%$ compared to full Albasia glulam beams. However, the timber material combination decrease ductioity of I and box section until $-26.27 \%$ and $-17.11 \%$ compared to full Alabsia glulam beams. The dominan failure modes of full Albasia solid rectangular section is bending failure. The dominan failure modes of full Albasia I and box section is combination of bending and shear failure. The dominan failure modes of combined Albasia-Meranti I and box section is combination of bending and shear failure.
\end{abstract}

Keywords : Glulam Beams, Bending Behaviour, I Section, Box Section, Albasia

\begin{abstract}
Abstrak
Balok kayu glulam digunakan untuk mendapatkan dimensi penampang yang dibutuhkan. Tujuan dari penelitian ini adalah mencari kapasitas lentur yang optimal berdasarkan bentuk penampang glulam dari 4 buah papan. Tujuan lainnya adalah membandingkan perilaku lentur balok glulam Albasia dan kombinasi jenis kayu Albasia-Meranti. Papan kayu disusun menjadi penampang persegi panjang, I, dan boks menggunakan perekat 'epoxy'. Dasar perencanaan bentuk penampang I dan boks adalah memiliki shear flow terkecil pada pertemuan web dan flens. Balok glulam kombinasi jenis kayu menggunakan kayu Meranti pada bagian flens penampang I dan boks. Pengujian lentur balok menggunakan metode 'third point loading'. Kapasitas lentur dan daktilitas balok glulam Albasia seluruhnya dengan penampang I adalah yang paling besar dibandingkan balok penampang persegi panjang dan boks glulam Albasia seluruhnya. Penggunaan kayu Meranti pada flens meningkatkan kapasitas lentur penampang I dan boks hingga $44.41 \%$ dan $57.56 \%$ dibandingkan balok glulam Albasia seluruhnya. Namun kombinasi tersebut menurunkan daktilitas penampang I dan boks hingga $-26.27 \%$ dan $-17.11 \%$ dibandingkan glulam Albasia seluruhnya. Moda kegagalan dominan pada penampang persegi panjang adalah kegagalan lentur. Moda kegagalan dominan pada penampang I dan boks Albasia adalah kombinasi kegagalan lentur dan geser. Moda kegagalan dominan pada penampang I dan boks glulam kombinasi Albasia-Meranti adalah kombinasi kegagalan lentur dan geser.
\end{abstract}

Kata kunci : Albasia, Balok Glulam, Penampang Boks, Penampang I, Perilaku Lentur

\section{Pendahuluan}

Keuntungan dari penggunaan material kayu diantaranya memiliki rasio kekuatan dengan berat yang tinggi, mudah dikerjakan, penghambat panas yg baik, memiliki aspek estetika yang baik, material terbarukan sepenuhnya, dan tidak berkontribusi dalam efek rumah kaca $[1,2]$. Kekurangan dari material kayu diantaranya, kayu memiliki properti bervariasi luas dan material anisotropik dengan kekuatan tegak lurus serat yang minim $[3,4]$. 
Berdasarkan kekurangan kayu, maka digunakan dilakukan rekayasa berupa kayu laminasi. Prinsip dari kayu laminasi adalah membagi kayu menjadi bagian kecil, kemudian menyatukan kembali. Hal ini seperti merekonstruksi kembali kayu sehingga sifat ortropik lebih minim dibandingkan kayu gelondongan [3]. Selain itu, glulam merupakan teknik yang baik untuk meminimalisir efek mata kayu, sudut serat, dan heterogenitas pada kayu [5].

Kayu laminasi tidak hanya dapat dibuat berpenampang persegi panjang, tetapi juga dapat dibuat dengan penampang lain seperti I dan Boks. Diperlukan penelitian untuk mengetahui perbandingan dari kekuatan balok kayu laminasi dengan perbedaan bentuk kayu laminasi.

\section{Studi Eksperimental}

\section{Dasar Pemilihan Penampang}

Sutedjo [6] menguji 6 spesimen penampang laminasi boks dengan 8 lembar per penampang. Sebelum dilakukan uji eksperimental, dilakukan prediksi kapasitas penampang. Pada penampang tersusun, salah satu hal yang perlu diperhitungkan adalah kapasitas lem dibandingkan shear flow 'aliran geser' [7]. Nilai yang menjadi konstanta pada perhitungan ini adalah kuat geser lem. Kemudian, dihitung besar kapasitas geser penampang keseluruhan pada saat lem akan lepas.

Pada kali ini dibandingkan 2 buah konfigurasi cara penyusunan untuk masing-masing penampang I dan boks. Pilihan penampang ditunjukan oleh Gambar 1. Dari hasil perhitungan, didapatkan konfigurasi tipe 1 memiliki shear flow terkecil. Sehingga, tipe 1 digunakan sebagai penampang yg diuji agar kegagalan delaminasi dapat diminimalisir.

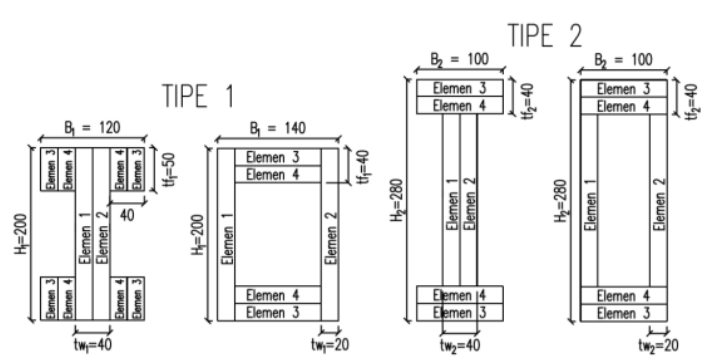

Gambar 1. Opsi penampang

\section{Persiapan Benda Uji}

Benda uji balok glulam dinamai berdasarkan kode penampang dan material penyusun. Kode " $A$ " menunjukkan kayu Albasia. Kode "M" menunjukkan penggunaan kayu Meranti pada flens. Kode balok glulam yang diuji antara lain:

a. PP1, PP2, PP3 - Persegi Panjang Albasia

b. IA1, IA2, IA3 - I Albasia

c. BA1, BA2, BA3 - Boks Albasia

d. IAM1, IAM2, IAM3 - I AlbasiaMeranti

e. BAM1, BAM2, BAM3 - Boks Albasia-Meranti

Balok glulam memerlukan 48 papan kayu Albasia dan 12 papan kayu Meranti dengan dimensi $20 \mathrm{~mm} \times 150 \mathrm{~mm} \times$ 2000mm. Pengujian tekan kayu Albasia dan Meranti memerlukan total 12 spesimen untuk arah sejajar serat, arah radial serat, dan arah tangensial serat.

Pengujian geser kayu Albasia dan Meranti memerlukan total 12 spesimen untuk arah long-rad, long-tan, dan rad-tan [8]. Pengujian geser perekat memerlukan total 24 spesimen kombinasi dari arah hubungan Albasia-Albasia, AlbasiaMeranti, dan Meranti-Meranti.

\section{Berat Jenis dan Kadar Air Kayu}

Sebelum dilakukan pengujian properti material, perlu dipastikan seluruh material sudah memiliki kadar air dibawah 19\% [9]. Maka dari itu, dilakukan pengujian kadar air dan berat jenis menggunakan oven. Dari hasil 
pengujian Kayu Albasia memiliki berat jenis antara 0.16 s.d. 0.38 , dengan ratarata 0.25 . Kayu Meranti memiliki berat jenis antara 0.46 s.d. 0.55 , dengan ratarata 0.49. Papan kayu Albasia yang digunakan memiliki rentang kadar air $11.26 \%$ s.d.13.62\%. Sedangkan, papan kayu Meranti memiliki rentang $11.75 \%$ s.d. $15.19 \%$.

\section{Pengujian Properti Material}

Pengujian properti material mengacu kepada ASTM D143-09. Berdasarkan ASTM D143-09 didapatkan properti material pada masing-masing arah. Selain itu juga dilakukan uji lentur nondestruktif untuk seluruh papan kayu. Tujuan dari pengujian ini adalah untuk mengetahui modulus elastisitas lentur statis, ESB dari seluruh papan kayu. Agar seluruh spesimen balok glulam memiliki hasil yang optimum, papan kayu dengan ESB rendah disatukan dengan ESB tinggi [10].

Hasil dari pengujian tekan adalah titik leleh dan modulus elastisitas. Berikut adalah titik leleh dan modulus elastisitas Albasia dan Meranti pada setiap arah:

\begin{tabular}{ccccc} 
Tabel 1. Properti kayu Albasia dan Meranti \\
\hline \multicolumn{4}{c}{ Albasia } & \multicolumn{2}{c}{ Meranti } \\
Arah & $\begin{array}{c}\mathbf{E} \\
(\mathbf{M P a})\end{array}$ & $\begin{array}{c}\boldsymbol{\sigma}_{\mathbf{y}} / \boldsymbol{\tau}_{\mathbf{y}} \\
(\mathbf{M P a})\end{array}$ & $\begin{array}{c}\mathbf{E} \\
(\mathbf{M P a})\end{array}$ & $\begin{array}{c}\boldsymbol{\sigma}_{\mathbf{y}} / \boldsymbol{\tau}_{\mathbf{y}} \\
(\mathbf{M P a})\end{array}$ \\
\hline \multirow{2}{*}{ L } & 1353.5 & 22.10 & 2887.0 & 28.92 \\
R & 179.5 & 2.61 & 312.2 & 10.68 \\
T & 179.5 & 3.60 & 340.4 & 8.45 \\
LR & - & 3.26 & - & 7.15 \\
LT & - & 4.25 & - & 8.61 \\
RT & - & 1.34 & - & 5.92
\end{tabular}

\section{Pembuatan Benda Uji}

Komposisi pembuatan elemen balok glulam mempertimbangkan 2 hal yaitu, modulus elastisitas lentur statis dan juga ketidaksempurnaan lengkungan kayu [11]. Dalam setiap elemen flens ataupun web, dicoba disusun satu per satu kayu yang menghasilkan celah paling minim. Proses merangkapkan kayu ini juga memperhitungkan kombinasi antara modulus elastisitas lentur statik $\left(\mathrm{E}_{\mathrm{SB}}\right)$ tinggi dan rendah.

Langkah pembuatan benda uji balok glulam adalah sebagai berikut

1. Menyusun papan kayu agar menghasilkan celah terkecil agar mengatasi kayu yang melengkung dan perekat lebih efektif.

2. Lapisi permukaan kayu dengan epoxy.

3. Tekan papan kayu dengan klem.

4. Haluskan dan ratakan permukaan samping papan kayu agar memiliki tinggi yang sama.

5. Berikan kelos kayu pada lokasi tumpuan dan beban. Guna dari kelos adalah agar seluruh penampang bekerja bersamaan.

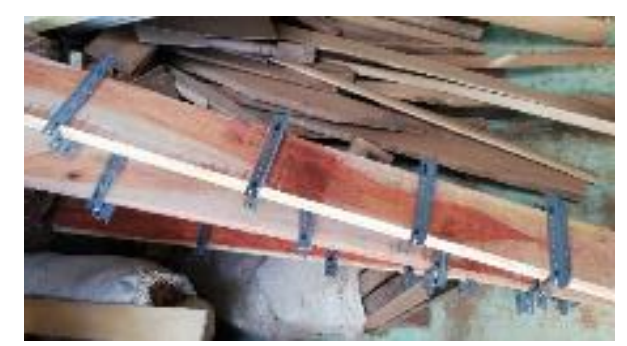

Gambar 2. Proses perekatan papan kayu dengan klem

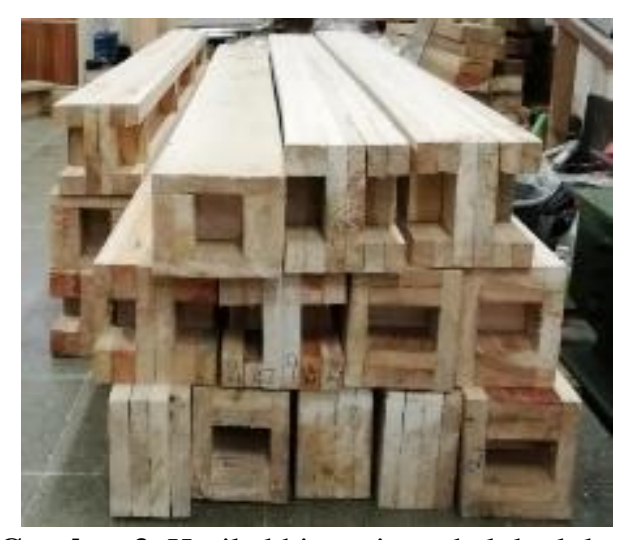

Gambar 3. Hasil akhir pesimen balok glulam

\section{Pengujian Lentur Balok Glulam}

Pengujian balok laminasi dilakukan menggunakan metode third point loading. Alat yang digunakan adalah UTM bermerek Hung Ta di Laboratorium Struktur Universitas Katolik Parahyangan. Kecepatan pembebanan diatur berdasarkan deformasi $6 \mathrm{~mm} /$ menit [6] dengan asumsi kuasi-statik [12]. Pada bagian tengah bentang balok uji dipasang 
LVDT untuk mencatat lendutan yang terjadi. Panjang total benda uji adalah $2000 \mathrm{~mm}$. Jarak antar tumpuan adalah $1800 \mathrm{~mm}$. Besaran terukur dari pengujian adalah lendutan dan beban yang diberikan oleh aktuator. Kedua besaran ini digunakan untuk melakukan analisis selanjutnya.

Tabel 2. Komposisi Elemen Penampang I dan Boks Albasia

\begin{tabular}{|c|c|c|c|c|c|c|c|}
\hline Elemen & Material & $\begin{array}{c}\text { IA1 } \\
{\left[\mathbf{E}_{\mathbf{S B}}\right]} \\
(\mathbf{M P a})\end{array}$ & $\begin{array}{c}\text { IA2 } \\
{\left[\mathbf{E}_{\mathbf{S B}]}\right]} \\
(\mathbf{M P a})\end{array}$ & $\begin{array}{c}\text { IA3 } \\
{\left[\mathbf{E}_{\mathbf{S B}}\right]} \\
(\mathbf{M P a})\end{array}$ & $\begin{array}{c}\text { BA1 } \\
{\left[\mathbf{E}_{\mathbf{S B}}\right]} \\
(\mathbf{M P a})\end{array}$ & $\begin{array}{c}\text { BA2 } \\
{\left[\mathbf{E}_{\mathbf{S B}}\right]} \\
(\mathbf{M P a})\end{array}$ & $\begin{array}{c}\text { BA3 } \\
{\left[\mathbf{E}_{\mathbf{S B}}\right]} \\
(\mathbf{M P a})\end{array}$ \\
\hline Elm 1 & Albasia & 2407.57 & 3102.39 & 3496.67 & 2524.24 & 3446.24 & 2422.57 \\
\hline Elm 2 & Albasia & 1912.37 & 2306.00 & 3478.26 & 2381.64 & 2206.24 & 3028.10 \\
\hline Elm 3 & Albasia & 2853.41 & 2521.17 & 3158.30 & 2864.86 & 1825.63 & 2823.96 \\
\hline Elm 4 & Albasia & 2308.23 & 1967.15 & 2401.55 & 3428.92 & 3747.94 & 2876.23 \\
\hline
\end{tabular}

Tabel 3. Komposisi Elemen Penampang I dan Boks Albasia-Meranti

\begin{tabular}{|c|c|c|c|c|c|c|c|}
\hline Elemen & Material & $\begin{array}{l}\text { IAM1 } \\
{\left[\mathbf{E}_{\mathbf{S B}}\right]} \\
(\mathrm{MPa})\end{array}$ & $\begin{array}{c}\text { IAM2 } \\
{\left[\mathrm{E}_{\mathrm{SB}}\right]} \\
(\mathrm{MPa})\end{array}$ & $\begin{array}{l}\text { IAM3 } \\
{\left[\mathbf{E}_{\mathbf{S B}]}\right]} \\
(\mathrm{MPa})\end{array}$ & $\begin{array}{c}\text { BAM1 } \\
{\left[\mathbf{E}_{S B}\right]} \\
(\mathrm{MPa})\end{array}$ & $\begin{array}{c}\text { BAM2 } \\
{\left[\mathrm{E}_{\mathrm{SB}}\right]} \\
(\mathrm{MPa})\end{array}$ & $\begin{array}{c}\text { BAM3 } \\
{\left[\mathbf{E}_{\mathrm{SB}}\right]} \\
(\mathbf{M P a})\end{array}$ \\
\hline Elm 1 & Albasia & 2378.43 & 2294.70 & 3050.00 & 3089.96 & 4083.46 & 4686.92 \\
\hline Elm 2 & Albasia & 3773.81 & 4076.40 & 3296.87 & 3389.35 & 2693.26 & 3208.41 \\
\hline Elm 3 & Meranti & 6316.63 & 5906.11 & 6606.33 & 6015.36 & 7301.08 & 6784.25 \\
\hline Elm 4 & Meranti & 7204.79 & 5903.91 & 6295.99 & 6454.63 & 6375.40 & 5957.97 \\
\hline
\end{tabular}

Tabel 4. Komposisi Elemen Penampang Persegi Panjang

\begin{tabular}{|c|c|c|c|c|}
\hline Elemen & Material & $\begin{array}{c}\text { PP1 } \\
{\left[\mathbf{E}_{\mathbf{S B}}\right]} \\
(\mathrm{MPa})\end{array}$ & $\begin{array}{c}\text { PP2 } \\
{\left[\mathbf{E}_{\mathrm{SB}}\right]} \\
(\mathrm{MPa})\end{array}$ & $\begin{array}{c}\mathbf{P P 3} \\
{\left[\mathbf{E}_{\mathrm{SB}}\right]} \\
(\mathbf{M P a})\end{array}$ \\
\hline Elm 1 & Albasia & 2537.27 & 3274.28 & 3863.25 \\
\hline Elm 2 & Albasia & 2860.12 & 2299.40 & 2230.57 \\
\hline Elm 3 & Meranti & 2473.30 & 1910.40 & 2399.96 \\
\hline Elm 4 & Meranti & 2088.88 & 1720.56 & 2461.35 \\
\hline
\end{tabular}

\section{Hasil dan Pembahasan}

Pengujian lentur balok glulam mengukur dua besaran yaitu beban dan peralihan. Peralihan diberikan secara inkremen. Titik akhir pengujian ditentukan pada saat beban menurun secara tiba-tiba. Hal ini juga ditandai dengan keruntuhan tibatiba pada spesimen.

Kurva beban-lendutan seolah-olah masih dalam fase strain hardening, namun sebenarnya terjadi keruntuhan tiba-tiba yang menyebabkan pengujian tidak dapat dilanjutkan.

Penentuan titik leleh adalah dengan metode energi sama besar. Kurva bebanlendutan dirumuskan dengan persamaan bilinier yang membagi luasan atas dan bawah sama besar. Sehingga, Beban Leleh dan Peralihan Leleh didapatkan dari titik belok pendekatan persamaan bilinier kurva.

Hasil analisis ditampilkan dalam tabulasi berupa perbandignan beban leleh $\left(\mathrm{P}_{\mathrm{y}}\right)$, beban puncak $\left(\mathrm{P}_{\max }\right)$, peralihan leleh $\left(\Delta_{\mathrm{y}}\right)$, peralihan puncak $\left(\Delta_{\max }\right)$, dan daktilitas $(\mu)$.

Moda kegagalan dari setiap penampang juga diamati untuk menyimpulkan tahanan dan daya servis [13].

\section{Balok Glulam Albasia Penampang Persegi Panjang}

Dari hasil pengujian benda uji PP3 memiliki nilai beban dan peralihan yang paling rendah, hal ini dikarenakan terjadi 
kegagalan produksi. Pada saat pelapisan terjadi pengenduran pengencang klem $\mathrm{F}$. Sehingga, terdapat celah antar papan yang menyebabkan transfer gaya antar papan menjadi tidak sempurna.

Benda uji PP1, PP2, dan PP3 memiliki bentuk kurva beban peralihan yang sama. Balok glulam Albasia dengan penampang persegi panjang menunjukkan adanya fase inelastis yang panjang. Tabel 5 menunjukkan hasil perbandingan specimen PP. Untuk menyederhanakan analisis, kurva beban peralihan dirubah kedalam persamaan bilinier.

Tabel 5. Hasil uji balok penampang Persegi Panjang Albasia

\begin{tabular}{ccccc}
\hline Benda Uji & PP1 & PP2 & PP3 & Rata-rata \\
\hline $\mathrm{P}_{\mathrm{y}}(\mathrm{N})$ & 26850.65 & 24899.83 & 19086.50 & 23612.33 \\
error & $13.71 \%$ & $5.45 \%$ & $-19.17 \%$ & - \\
$\mathrm{P}_{\max }(\mathrm{N})$ & 32483.51 & 29852.38 & 22098.59 & 28144.83 \\
error & $15.42 \%$ & $6.07 \%$ & $-21.48 \%$ & - \\
$\Delta_{\mathrm{y}}(\mathrm{mm})$ & 24.51 & 23.87 & 16.74 & 21.71 \\
error & $12.92 \%$ & $9.95 \%$ & $-22.87 \%$ & - \\
$\Delta_{\max }(\mathrm{mm})$ & 50.19 & 40.63 & 22.44 & 37.75 \\
error & $32.94 \%$ & $7.62 \%$ & $-40.56 \%$ & - \\
$\mu$, daktilitas & 2.05 & 1.70 & 1.34 & 1.70 \\
error & $20.67 \%$ & $0.33 \%$ & $-21.01 \%$ & - \\
\hline
\end{tabular}

\section{Balok Glulam Albasia Penampang I}

Dari hasil pengujian benda uji IA2 memiliki nilai beban yang paling rendah. Hal ini dikarenakan, terdapat cacat mata kayu pada bagian web balok. Benda uji IA1, IA2, dan IA3 memiliki bentuk kurva beban peralihan yang sama, terutama pada fase elastis. Balok glulam Albasia dengan penampang I menunjukkan adanya fase inelastis yang panjang. Tabel 6 menunjukkan hasil perbandingan specimen IA.

Tabel 6. Hasil uji balok penampang I Albasia

\begin{tabular}{ccccc}
\hline Benda Uji & IA1 & IA2 & IA3 & Rata-rata \\
\hline $\mathrm{P}_{\mathrm{y}}(\mathrm{N})$ & 29472.97 & 23323.34 & 31584.74 & 28127.02 \\
error & $4.79 \%$ & $-17.08 \%$ & $12.29 \%$ & - \\
$\mathrm{P}_{\max }(\mathrm{N})$ & 34084.56 & 24439.34 & 31938.36 & 30154.09 \\
error & $13.03 \%$ & $-18.95 \%$ & $5.92 \%$ & - \\
$\Delta_{\mathrm{y}}(\mathrm{mm})$ & 23.08 & 19.24 & 24.52 & 21.71 \\
error & $3.60 \%$ & $-13.64 \%$ & $10.04 \%$ & - \\
$\Delta_{\max }(\mathrm{mm})$ & 44.40 & 23.10 & 31.00 & 32.83 \\
error & $35.23 \%$ & $-29.64 \%$ & $-5.58 \%$ & - \\
$\mu$, daktilitas & 1.92 & 1.20 & 1.26 & 1.46 \\
error & $31.49 \%$ & $-17.93 \%$ & $-13.57 \%$ & - \\
\hline
\end{tabular}

\section{Balok Glulam Albasia - Meranti Penampang I}

Dari hasil pengujian benda uji IAM1, IAM2, dan IAM3 memiliki nilai beban peralihan dan bentuk kurva yang hampir sama. Balok glulam Albasia-Meranti dengan penampang I menunjukkan adanya fase inelastis yang pendek, dengan bentuk kurva yang gagal tibatiba. Tabel 7 menunjukkan hasil perbandingan specimen IAM. 
Alvianti, Johannes Adhijoso Tjondro, Studi Eksperimental...

Tabel 7. Hasil uji balok penampang I Albasia-Meranti

\begin{tabular}{ccccc}
\hline Benda Uji & IAM1 & IAM2 & IAM3 & Rata-rata \\
\hline $\mathrm{P}_{\mathrm{y}}(\mathrm{N})$ & 42052.98 & 38304.60 & 35492.20 & 38616.59 \\
error & $8.90 \%$ & $-0.81 \%$ & $-8.09 \%$ & - \\
$\mathrm{P}_{\max }(\mathrm{N})$ & 46902.88 & 43865.42 & 41609.29 & 44125.86 \\
error & $6.29 \%$ & $-0.59 \%$ & $-5.70 \%$ & - \\
$\Delta_{\mathrm{y}}(\mathrm{mm})$ & 21.71 & 17.70 & 18.00 & 19.14 \\
error & $13.45 \%$ & $-7.52 \%$ & $-5.93 \%$ & - \\
$\Delta_{\text {max }}(\mathrm{mm})$ & 26.49 & 24.64 & 24.28 & 25.14 \\
error & $35.23 \%$ & $-29.64 \%$ & $-5.58 \%$ & - \\
$\mu$, daktilitas & 1.22 & 1.39 & 1.35 & 1.32 \\
error & $-7.59 \%$ & $5.44 \%$ & $2.15 \%$ & - \\
\hline & & & & \\
\hline
\end{tabular}

\section{Balok Glulam Albasia Penampang Boks}

Dari hasil pengujian benda uji BA3 memiliki nilai peralihan yang tertinggi, dikarenakan dua spesimen lain memiliki cacat mata kayu. Benda uji BA1, BA2, dan BA3 memiliki bentuk kurva beban peralihan yang sama. Balok glulam. Albasia dengan penampang boks menunjukkan adanya fase inelastis yang panjang. Tabel 8 menunjukkan hasil perbandingan spesimen BA.

\section{Balok Glulam Albasia-Meranti Penampang Boks}

Dari hasil pengujian benda uji BAM1, BAM2, dan BAM3 memiliki nilai beban peralihan dan bentuk kurva yang hampir

Tabel 8. Hasi uji balok penampang boks Albasia

\begin{tabular}{ccccc}
\hline Benda Uji & BA1 & BA2 & BA3 & Rata-rata \\
\hline $\mathrm{P}_{\mathrm{y}}(\mathrm{N})$ & 24718.94 & 21366.81 & 30732.30 & 25606.02 \\
error & $-3.46 \%$ & $-16.56 \%$ & $20.02 \%$ & - \\
$\mathrm{P}_{\max }(\mathrm{N})$ & 28610.92 & 23430.29 & 35567.38 & 29202.86 \\
error & $-2.03 \%$ & $-19.77 \%$ & $21.79 \%$ & - \\
$\Delta_{\mathrm{y}}(\mathrm{mm})$ & 18.32 & 15.80 & 23.96 & 19.36 \\
error & $-5.35 \%$ & $-18.39 \%$ & $23.74 \%$ & - \\
$\Delta_{\text {max }}(\mathrm{mm})$ & 25.12 & 19.68 & 49.82 & 31.54 \\
error & $-20.36 \%$ & $-37.60 \%$ & $57.96 \%$ & - \\
$\mu$, daktilitas & 1.37 & 1.25 & 2.08 & 1.57 \\
error & $-12.43 \%$ & $-20.43 \%$ & $32.86 \%$ & - \\
\hline
\end{tabular}

Tabel 9. Hasi uji balok penampang boks Albasia-Meranti

\begin{tabular}{ccccc}
\hline Benda Uji & BA1 & BA2 & BA3 & Rata-rata \\
\hline $\mathrm{P}_{\mathrm{y}}(\mathrm{N})$ & 37220.01 & 36614.34 & 44521.06 & 39451.80 \\
error & $-5.66 \%$ & $-7.19 \%$ & $12.85 \%$ & - \\
$\mathrm{P}_{\max }(\mathrm{N})$ & 46182.19 & 41888.60 & 49964.84 & 46011.87 \\
error & $0.37 \%$ & $-8.96 \%$ & $8.59 \%$ & - \\
$\Delta_{\mathrm{y}}(\mathrm{mm})$ & 20.04 & 17.54 & 20.74 & 19.44 \\
error & $3.09 \%$ & $-9.77 \%$ & $6.68 \%$ & - \\
$\Delta_{\max }(\mathrm{mm})$ & 27.58 & 21.00 & 27.36 & 25.31 \\
error & $8.95 \%$ & $-17.04 \%$ & $8.09 \%$ & - \\
$\mu$, daktilitas & 1.38 & 1.20 & 1.32 & 1.30 \\
error & $6.06 \%$ & $-7.73 \%$ & $1.68 \%$ & - \\
\hline
\end{tabular}




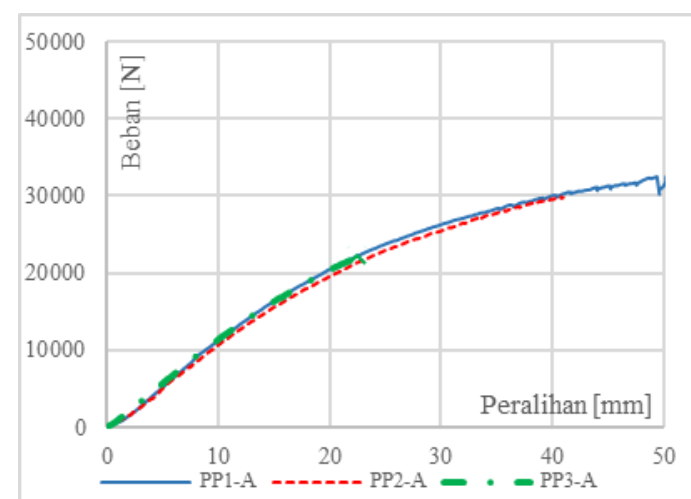

Gambar 4. Hasil pengujian Balok Glulam Penampang Persegi Panjang
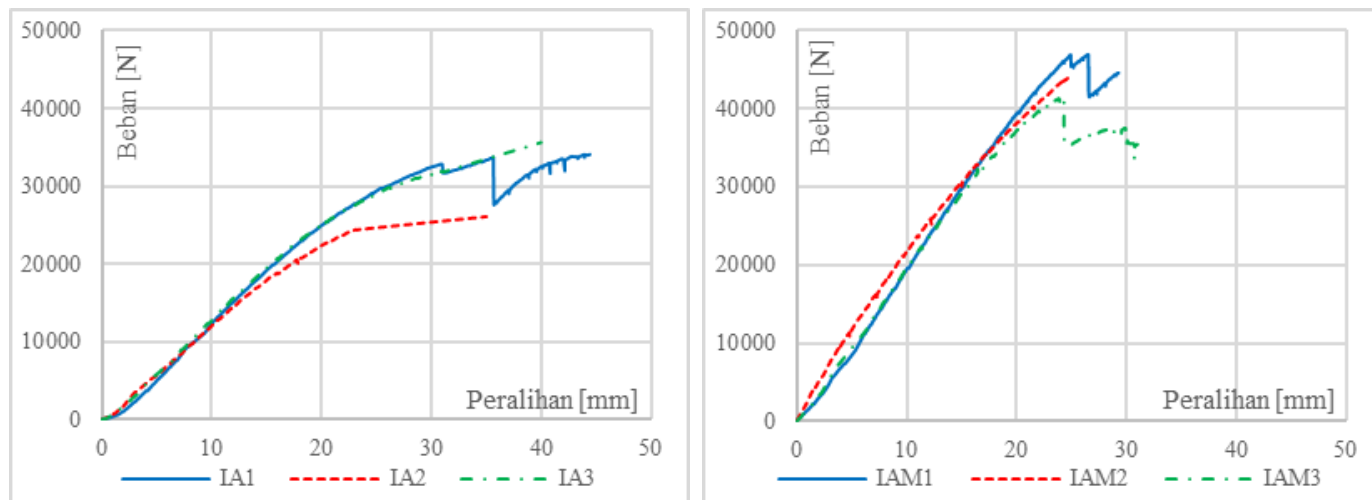

Gambar 5. Hasil pengujian Balok Glulam Penampang I
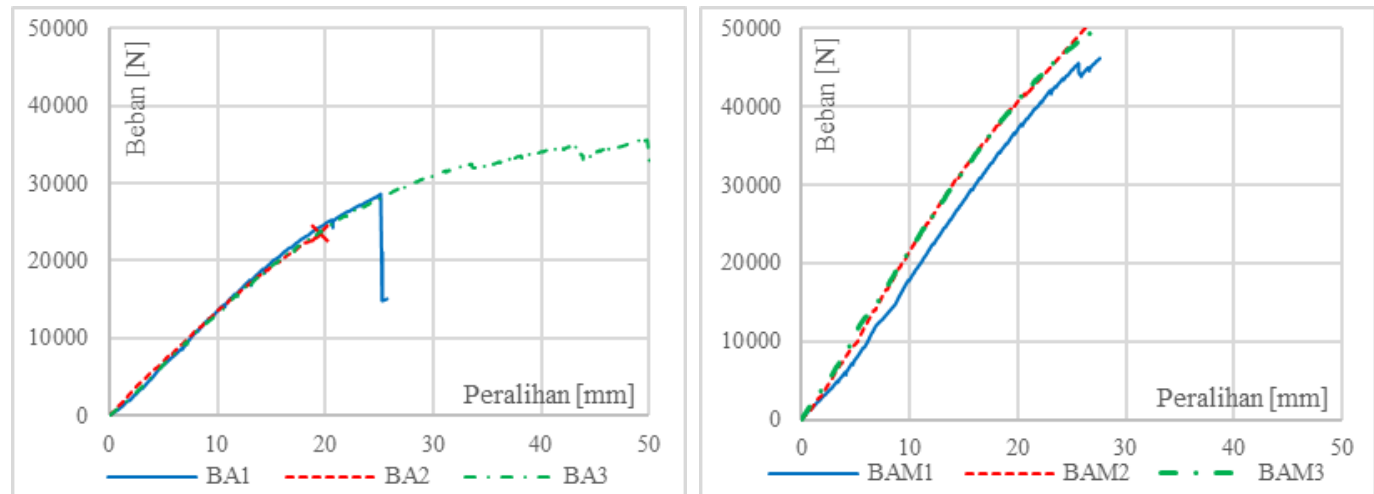

Gambar 6. Hasil pengujian Balok Glulam Penampang Boks

\section{Analisis Moda Kegagalan}

\section{Moda Kegagalan Balok Glulam Albasia Penampang Persegi Panjang}

Moda kegagalan pada ketiga balok glulam Albasia penampang persegi panjang adalah Simple Tension dan Long-fibred tension failure parallel to the grain. Moda kegagalan balok glulam ini didominasi kegagalan lentur. Kegagalan lentur saja ditandai retak hanya terjadi pada serat tarik.
Benda uji PP1, PP2, dan PP3 menunjukkan moda kegagalan yang hampir sama. Sehingga, dapat dikatakan memiliki konsistensi yang baik. Benda uji PP3 mengalami delaminasi, dikarenakan kegagalan produksi pada saat proses perekatan.

\section{Moda Kegagalan Balok Glulam Albasia Penampang I}

Moda kegagalan pada ketiga pada balok glulam Albasia penampang I adalah dominan Simple Tension dikombinasi 
Horizontal Shear pada web. Sedangkan pada flens terjadi Long-fibred tension failure parallel to the grain. Moda kegagalan yang terjadi adalah kombinasi kegagalan lentur dan geser. Moda kegagalannya didominasi kegagalan lentur. Moda kegagalan geser muncul, dikarenakan luas area berkontribusi menahan tegangan geser berkurang dibandingkan persegi panjang. Kegagalan geser ditandai terjadi retak mengarah horizontal.

Benda uji IA1, IA2, dan IA3 menunjukkan moda kegagalan yang hampir sama. Sehingga, dapat dikatakan memiliki konsistensi yang baik. Benda uji IA2 memiliki cacat mata kayu, sehingga memiliki kapasitas lentur yang paling kecil.

\section{Moda Kegagalan Balok Glulam Albasia- Meranti Penampang I}

Moda kegagalan pada ketiga pada balok glulam Albasia-Meranti penampang I adalah dominan Horizontal Shear dikombinasi Simple Tension pada web. Sedangkan pada flens terjadi Longfibred tension failure parallel to the grain. Moda kegagalan terjadi adalah kombinasi kegagalan geser dan lentur. Moda kegagalannya didominasi kegagalan geser. Dominan kegagalan geser ditandai terjadi retak horizontal shear yang panjang dan besar.

Benda uji IAM1, IAM2, dan IAM3 menunjukkan moda kegagalan yang hampir sama. Sehingga, dapat dikatakan memiliki konsistensi yang baik.

\section{Moda Kegagalan Balok Glulam Albasia Penampang Boks}

Moda kegagalan pada ketiga pada balok glulam Albasia penampang Boks adalah dominan Simple Tension dikombinasi Horizontal Shear pada web. Sedangkan pada flens terjadi Long-fibred tension failure parallel to the grain. Moda kegagalan yang terjadi adalah kombinasi kegagalan geser dan lentur. Moda kegagalannya didominasi kegagalan lentur. Kegagalan geser ditandai terjadi retak horizontal shear pada ujung balok.

Benda uji BA1, BA2, dan BA3 menunjukkan moda kegagalan yang hampir sama. Sehingga, dapat dikatakan memiliki konsistensi yang baik. Benda uji BA1 dan BA2 memiliki cacat mata kayu.

\section{Moda Kegagalan Balok Glulam Albasia Penampang Boks}

Moda kegagalan pada ketiga pada balok glulam Albasia-Meranti penampang Boks adalah dominan Horizontal Shear dikombinasi Simple Tension pada web. Sedangkan pada flens terjadi Longfibred tension failure parallel to the grain. Moda kegagalan yang terjadi balok glulam ini adalah kombinasi kegagalan geser dan lentur. Dominan kegagalan geser ditandai terjadi retak horizontal shear yang panjang dan besar.

Benda uji BAM1, BAM2, dan BAM3 menunjukkan moda kegagalan yang hampir sama. Sehingga, dapat dikatakan memiliki konsistensi yang baik.

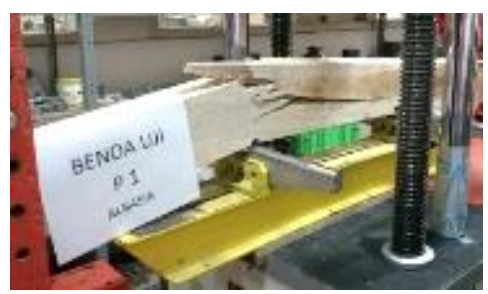

( PP1 )

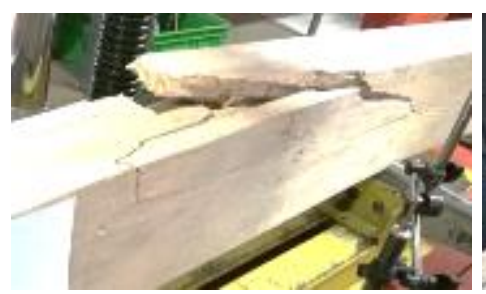

( PP2 )

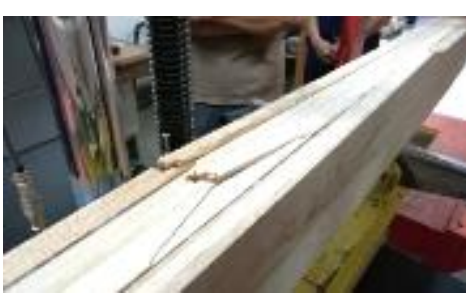

( PP3 )

Gambar 7. Moda kegagalan spesimen Balok Glulam Albasia Penampang Persegi Panjang 


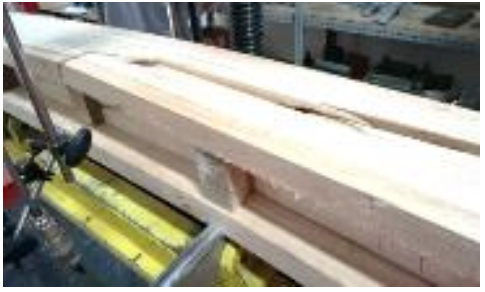

( IA1 )

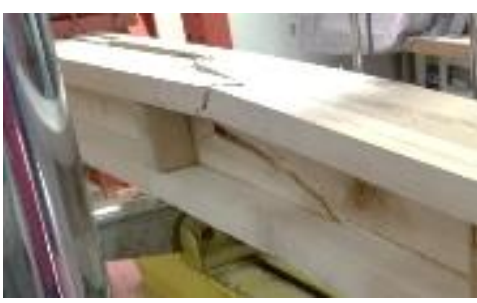

( IA2 )

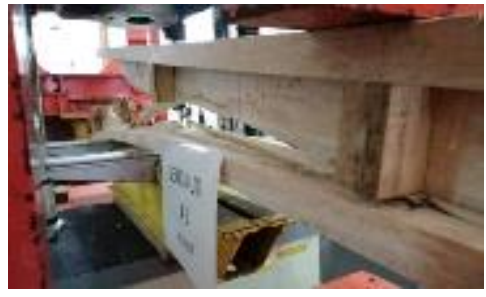

( IA3 )

Gambar 8. Moda kegagalan spesimen Balok Glulam Albasia Penampang I

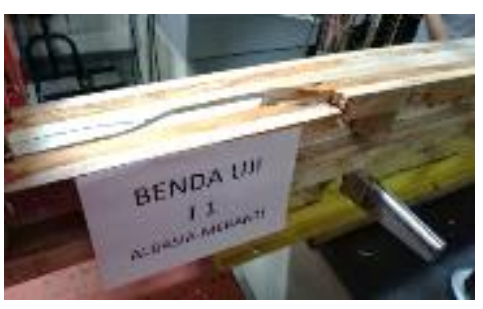

( IAM1 )

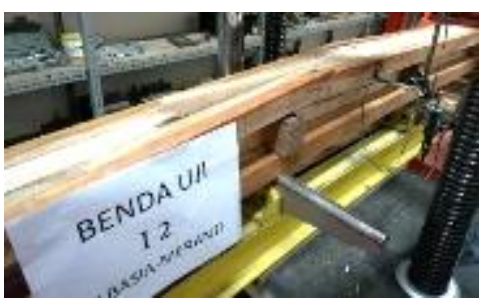

( IAM2 )

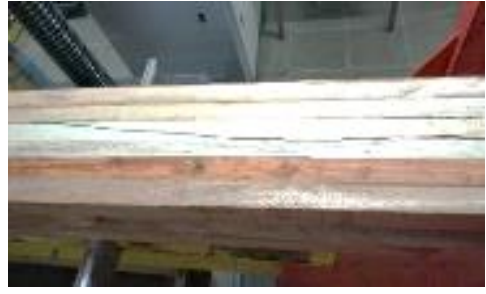

( IAM3 )

Gambar 9. Moda kegagalan spesimen Balok Glulam Albasia-Meranti Penampang I

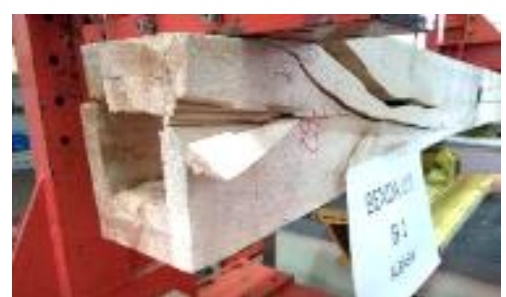

( BA1 )

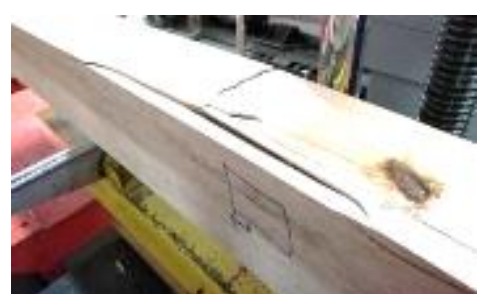

( BA2 )

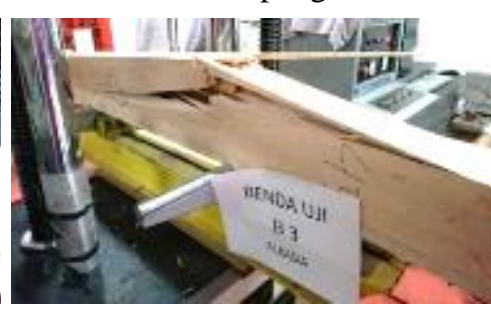

( BA3 )

Gambar 10. Moda kegagalan spesimen Balok Glulam Albasia Penampang Boks

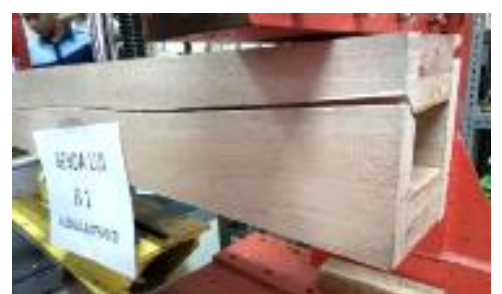

( BAM1 )

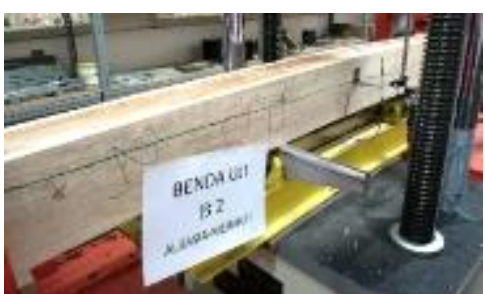

( BAM2 )

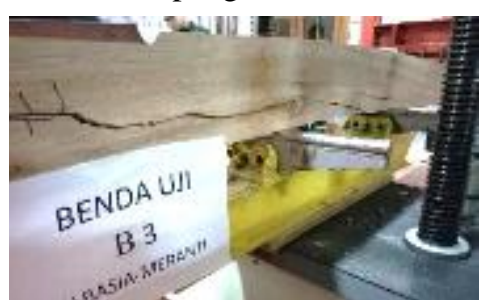

( BAM3 )

Gambar 11. Moda kegagalan spesimen Balok Glulam Albasia-Meranti Penampang Boks

\section{Perbandingan Hasil Pengujian Lentur Balok Glulam}

\section{Perbandingan Kapasitas Lentur Antar Penampang Kayu Balok Glulam Albasia}

Kurva bilinier dari Tabel 5 s.d. Tabel 9 dirangkum

Tabel 10 dan Tabel 11. Nilai yang ditampilkan dalam tabel merupakan ratarata masing-masing ketiga benda uji. Berdasarkan perbandingan, penampang I memiliki beban leleh $\left(\mathrm{P}_{\mathrm{y}}\right)$, beban puncak $\left(\mathrm{P}_{\max }\right)$, peralihan leleh $\left(\Delta_{\mathrm{y}}\right)$, peralihan puncak $\left(\Delta_{\max }\right)$, dan daktilitas $(\mu)$ terbesar.
Penggunaan bentuk penampang I dan boks pada balok glulam dapat meningkatkan kapasitas beban dibandingkan penampang persegi. Peningkatan kapasitas beban leleh penampang I dan boks dibandingkan persegi panjang sebesar $19.12 \%$ dan 8.44\%. Peningkatan kapasitas beban maksimum penampang I dan boks adalah sebesar $8.57 \%$ dan $3.76 \%$. Penggunaan penampang boks menurunkan daktilitas dan peralihan balok dibandingkan penampang persegi panjang dan I. 
Tabel 10. Perbandingan Beban dan Peralihan Bilinier Semua Penampang Kayu Albasia

\begin{tabular}{cccc}
\hline Benda Uji & PP & I & Box \\
\hline $\mathrm{P}_{\mathrm{y}}(\mathrm{N})$ & 23612.33 & 28127.02 & 25606.02 \\
$\mathrm{P}_{\max }(\mathrm{N})$ & 28144.83 & 30556.27 & 29202.86 \\
$\Delta_{\mathrm{y}}(\mathrm{mm})$ & 21.71 & 22.28 & 19.36 \\
$\Delta_{\max }(\mathrm{mm})$ & 37.75 & 39.79 & 31.54 \\
$\mu$, daktilitas & 1.70 & 1.79 & 1.57 \\
\hline
\end{tabular}

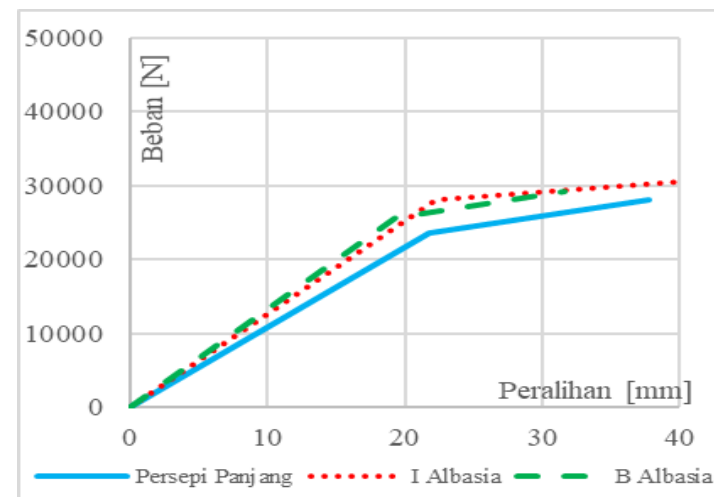

Gambar 12. Perbandingan kurva bilinier balok glulam Albasia penampang Persegi, I, dan Boks
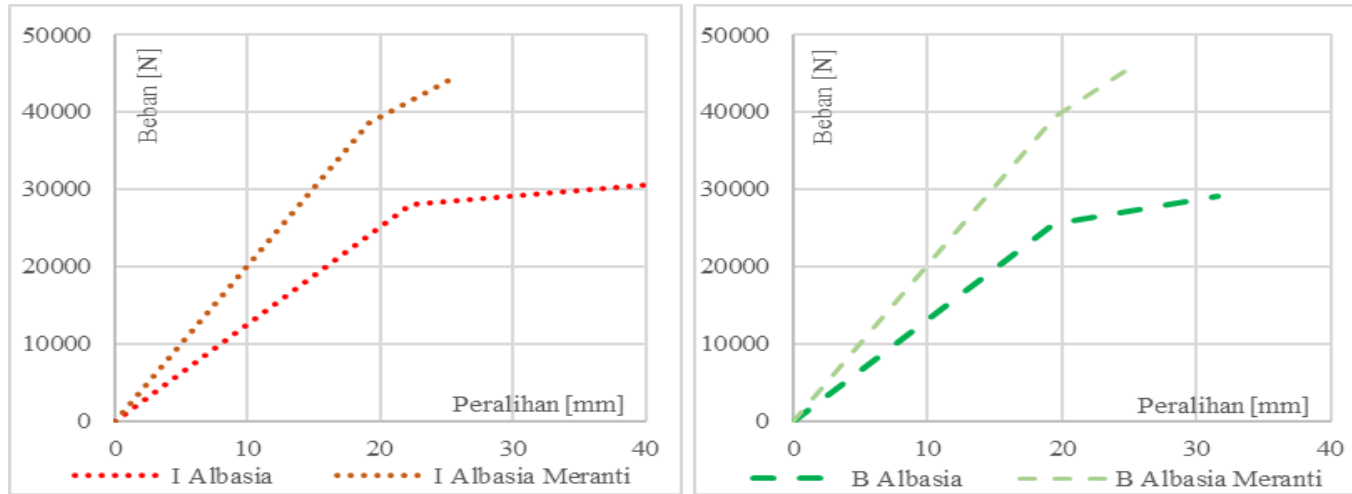

Gambar 13. Perbandingan kurva bilinier balok glulam Albasia dan Albasia-Meranti

\section{Perbandingan Kapasitas Lentur Balok Glulam Kombinasi Albasia-Meranti}

Kurva bilinier dari Tabel 5 s.d. Tabel 9 dirangkum

Tabel 10 dan Tabel 11. Nilai yang ditampilkan dalam tabel merupakan ratarata masing-masing ketiga benda uji. Berdasarkan perbandingan, penggunaan kayu Meranti sebagai flens dapat meningkatkan kapasitas beban leleh $\left(\mathrm{P}_{\mathrm{y}}\right)$ dan beban puncak $\left(\mathrm{P}_{\max }\right)$. Peningkatan kapasitas beban puncak $\left(\mathrm{P}_{\max }\right)$ penampang I dan boks $44.41 \%$ dan $57.56 \%$.

Sedangkan penggunaan kayu Meranti sebagai flens mengurangi peralihan leleh $\left(\Delta_{\mathrm{y}}\right)$, peralihan puncak $\left(\Delta_{\max }\right)$, dan daktilitas $(\mu)$ terbesar. Pengurangan peralihan puncak $\left(\Delta_{\max }\right)$ penampang I dan boks $-36.83 \%$ dan $-19.74 \%$.

Tabel 11. Perbandingan Beban dan Peralihan Bilinier Kayu Albasia-Meranti

\begin{tabular}{ccccc}
\hline Benda Uji & IA & IAM & BA & BAM \\
\hline $\mathrm{P}_{\mathrm{y}}(\mathrm{N})$ & 28127.02 & 38616.59 & 25606.02 & 39451.8 \\
rasio & \multicolumn{2}{c}{$37.29 \%$} & \multicolumn{2}{c}{$54.07 \%$} \\
$\mathrm{P}_{\max }(\mathrm{N})$ & 30556.27 & 44125.86 & 29202.86 & 46011.87 \\
rasio & \multicolumn{2}{c}{$44.41 \%$} & \multicolumn{2}{c}{$57.56 \%$} \\
\hline
\end{tabular}


POLITEKNOLOGI VOL. 20 NO. 1 JANUARI 2021

\begin{tabular}{|c|c|c|c|c|}
\hline Benda Uji & IA & IAM & $\mathbf{B A}$ & BAM \\
\hline$\Delta_{\mathrm{y}}(\mathrm{mm})$ & 22.28 & 19.14 & 19.36 & 19.44 \\
\hline rasio & \multicolumn{2}{|c|}{$-14.12 \%$} & \multicolumn{2}{|c|}{$0.41 \%$} \\
\hline$\Delta_{\max }(\mathrm{mm})$ & 39.79 & 25.14 & 31.54 & 25.31 \\
\hline $\begin{array}{c}\text { rasio } \\
\mu, \text { daktilitas }\end{array}$ & \multicolumn{2}{|c|}{$-36.83 \%$} & $-19.74 \%$ & $\%$ \\
\hline Rasio & \multicolumn{2}{|c|}{$-26.27 \%$} & \multicolumn{2}{|c|}{$-17.11 \%$} \\
\hline
\end{tabular}

\section{Faktor Koreksi Kekakuan}

Lendutan hasil pengujian lentur balok dibandingkan dengan lendutan Teori Balok Euler. Nilai modulus elastisitas yang digunakan berdasarkan hasil pengujian lentur non destruktif. Perbandingan yang dilakukan adalah membandingkan lendutan pada saat beban leleh kurva bilinier dengan rumus lendutan elastis [14]. Dengan membanding-kan lendutan tersebut, maka didapatkan nilai faktor koreksi untuk kekakuan penampang balok glulam. Faktor koreksi untuk kekakuan balok glulam ditunjukan pada tabel berikut.

Tabel 12. Faktor koreksi kekakuan untuk analisis lendutan

\begin{tabular}{|c|c|c|c|c|c|c|}
\hline \multirow[b]{2}{*}{$\begin{array}{c}\text { Benda } \\
\text { Uji }\end{array}$} & EI & $\mathbf{P}_{\mathbf{y}}$ & $\Delta_{y}$ & $\Delta_{\text {perhitungan }}$ & $\mathbf{k}$ & $\mathbf{k}_{\text {rata-rata }}$ \\
\hline & {$\left[\mathrm{Nm}^{2}\right]$} & {$[\mathbf{N}]$} & {$[\mathrm{mm}]$} & {$[\mathrm{mm}]$} & $\begin{array}{c}\text { (Faktor } \\
\text { koreksi } \\
\text { EI) }\end{array}$ & $\begin{array}{l}\text { (Faktor } \\
\text { koreksi } \\
\text { EI) }\end{array}$ \\
\hline PP1 & 164747.31 & 26850.65 & 24.51 & 14.67 & 0.598 & \multirow{3}{*}{0.597} \\
\hline PP2 & 151176.53 & 24899.83 & 23.87 & 14.82 & 0.621 & \\
\hline PP3 & 179033.46 & 19086.50 & 16.74 & 9.60 & 0.573 & \\
\hline IA1 & 205070.86 & 29472.97 & 23.08 & 12.93 & 0.560 & \multirow{3}{*}{0.585} \\
\hline IA 2 & 178544.91 & 23323.34 & 19.24 & 11.76 & 0.611 & \\
\hline IA3 & 198322.42 & 31584.74 & 24.52 & 14.33 & 0.585 & \\
\hline BA1 & 208765.29 & 24718.94 & 18.32 & 10.66 & 0.582 & \multirow{3}{*}{0.582} \\
\hline BA2 & 180803.32 & 21366.81 & 15.80 & 10.64 & 0.673 & \\
\hline BA3 & 234343.01 & 30732.30 & 23.95 & 11.80 & 0.493 & \\
\hline IAM1 & 244774.80 & 42052.98 & 21.71 & 15.46 & 0.712 & \multirow{3}{*}{0.727} \\
\hline IAM2 & 234050.66 & 38304.60 & 17.70 & 14.73 & 0.832 & \\
\hline IAM3 & 278433.35 & 35492.20 & 18.00 & 11.47 & 0.637 & \\
\hline BAM1 & 265432.77 & 37220.00 & 20.04 & 12.62 & 0.630 & \multirow{3}{*}{0.617} \\
\hline BAM2 & 319762.19 & 36614.34 & 17.54 & 10.30 & 0.588 & \\
\hline BAM3 & 305353.72 & 44521.06 & 20.74 & 13.12 & 0.633 & \\
\hline
\end{tabular}

\section{KESIMPULAN}

\section{Perbandingan Balok Glulam Albasia}

Dari hasil pengujian dan analisis diatas dapat ditarik beberapa kesimpulan diantaranya:

a. Balok glulam Albasia penampang I memiliki kapasitas lentur dan daktilitas yang paling besar dibandingkan penampang persegi panjang dan boks. Sehingga, balok glulam dengan 4 papan kayu paling efektif disusun menjadi penampang I.

b. Balok glulam Albasia penampang I efektif dalam meningkatkan kapasitas lentur penampang. Kenaikan kapasitas lentur dan daktilitas penampang I dibandingkan penampang persegi panjang sebesar $19.12 \%$ dan $5.56 \%$.

c. Balok glulam Albasia penampang boks tidak efektif dalam meningkatkan kapasitas lentur penampang. Kenaikan kapasitas 
lentur penampang boks dibandingkan penampang persegi panjang sebesar 8.44\%. Namun, penggunaan penampang boks menurunkan daktilitas hingga $-7.74 \%$.

\section{Perbandingan Balok Glulam Albasia- Meranti}

Dari hasil pengujian dan analisis diatas dapat ditarik beberapa kesimpulan diantaranya:

a. Penggunaan Kayu Meranti pada flens paling efektif jikalau digunakan pada penampang boks. Hal ini dikarenakan, pada penampang boks Kayu Meranti mampu meningkatkan kapasitas lentur paling besar dan menurunkan daktilitas paling sedikit.

b. Penggunaan Kayu Meranti pada flens balok glulam penampang I dan boks mampu meningkatkan kapasitas lentur hingga $44.41 \%$ dan $57.56 \%$.

c. Penggunaan Kayu Meranti pada flens balok glulam penampang I dan boks menurunkan daktilitas penampang I dan boks sebesar $-26.27 \%$ dan $17.11 \%$.

\section{Moda Kegagalan}

Dari hasil pengujian dan analisis diatas dapat ditarik beberapa kesimpulan diantaranya:

a. Moda kegagalan balok glulam Albasia penampang persegi panjang adalah Simple Tension dan Longfibred tension failure parallel to the grain.

b. Moda kegagalan balok glulam Albasia penampang I dan boks adalah dominan Simple Tension dikombinasi Horizontal Shear pada web. Sedangkan pada flens terjadi Longfibred tension failure parallel to the grain.

c. Moda kegagalan balok glulam Albasia-Meranti penampang I dan boks adalah dominan Horizontal Shear dikombinasi Simple Tension pada web. Sedangkan pada flens terjadi Long-fibred tension failure parallel to the grain.

d. Moda kegagalan balok glulam Albasia penampang persegi panjang, I, dan boks adalah dominan kegagalan lentur dengan tambahan kegagalan geser.

e. Moda kegagalan balok glulam Albasia-Meranti penampang I dan boks adalah kegagalan geser.

\section{Faktor Koreksi Kekakuan}

Dari hasil pengujian dan analisis diatas dapat ditarik beberapa kesimpulan diantaranya:

a. Nilai faktor koreksi kekakuan pada balok glulam kayu albasia penampang persegi panjang, I dan boks adalah sebesar $0.597,0.585$, dan 0.582 . Nilai rata-rata dari ketiganya sebesar 0.588 .

b. Nilai faktor koreksi kekakuan pada balok glulam kayu kombinasi penampang I dan boks adalah sebesar 0.727 dan 0.617 .

\section{Ucapan Terima kasih}

Terima kasih kepada Universitas Katolik Parahyangan sebagai institusi pendidikan yang memberikan fasilitas dalam penelitian

\section{Daftar Pustaka}

[1] N. K. A. Artiningsih, Pemanfaatan Bambu Pada Konstruksi Bangunan Berdampak Positip Bagi Lingkungan, Indonesia: Metana, 8(01), 2012.

[2] N. N. S. S. Y. S. H. I. Sulistyawati, "Kekakuan dan kekuatan lentur maksimum balok glulam dan utuh kayu akasia," Journal of Civil Engineering, 15(3), pp. 113-122, 2008.

[3] E. Serrano, "Adhesive Joints in Timber Engineering - Modelling and Testing of Fracture 
Properties," Doctoral Thesis, Lund University, Lund, Swedia, 2000.

[4] V. G. D.E. Kretschman, Wood Handbook - Wood as an Engineering Material, Madison, Wisconsin.: Centennial ed. Forest Product Laboratory, 2010.

[5] E. Cesar, "Bamboo-Reinforced Glulam Beams: An Alternative to Fiberglass-Reinforced Glulam Beams," Dyna rev.fac.nac.minas vol.79, p. 174, 2012.

[6] S. Krisnadi, "Studi Eksperimental dan Numerikal Perilaku Lentur Balok Boks Glulam. Thesis.," Universitas Katolik Parahyangan, Bandung, 2017.

[7] Y. W. Cook R.D., Advanced Mechanics of Materials, 2nd Edition, New Jersey: Prentice Hall, Inc., Upper Saddle River, 1999.

[8] A. T. O. R. S. Bambang Suryoatmono, "Evaluation of Moduli of Elasticity and Damping Ratios of Some Indonesian Species Using the Free Vibration Method," in Proceedings of the 15th International Symposium on Nondestructive Testing of Wood, Duluth Minessota, Amerika Serikat, 2007.

[9] ASTM International, ASTM D143-09 : Standard Test Methods for small Clear Speciments of Timber, Amerika: ASTM International, 2000.

[10] J. A. Tjondro, "The Shear Strength and Stress Distribution in The Glue Adhesive Between Hardwoods Lamina," The 3rd Internasional Symposium of IwoRS, Jogjakarta., 2011.

[11] A. T. Bambang Suryoatmono, "Lateral-torsional Buckling of Orthotropic Rectangular Section," World Conference on Timber
Engineering, Miyazaki, Japan., 2008.

[12] S. R. Khorasan, "Finite-Element Simulations of Glulam Beams with Natural Cracks.," Master Thesis, Blekinge Institue of Technology, Karlskrona, Swedia, 2012.

[13] B. F. A. M. H. Steffen Franke, "Failure Modes and Reinforcement Techniques for Timber Beams - State of the Art," Construction and Building Materials, vol. 97, no. 0950-0618, pp. 2-13, 2015.

[14] Departemen Pekerjaan Umum:, SNI 7973:2013, Spesifikasi Desain untuk Konstruksi Kayu, Jakarta, Indonesia.: Badan Standarisasi Nasional, 2013.

[15] T. M. S. M. I. L. E. Hunggurami, "Pengujian Kuat Tekan Dan Kuat Lentur Material Pengganti Kayu dengan Campuran Serat Nilon," Jurnal Teknik Sipil, 4(2), pp. 209216, 2015. 